\title{
On the relationship between print and mobile channels for newspapers
}

\author{
Patrick Winter $^{1} \cdot$ Paul Alpar ${ }^{1}$
}

Received: 23 December 2016 / Accepted: 19 July 2017 /Published online: 11 August 2017

(C) The Author(s) 2017. This article is an open access publication

\begin{abstract}
The business model of traditional media has come under attack due to digital delivery channels. In this paper, we analyze how a mobile app affects the lifetimes and lifetime values of customers of print media. We use subscription data and develop a model based on survival analysis that captures the interdependence between these two content delivery channels. We apply our model to a large dataset of a publisher who offers a newspaper in a print version and a version as a mobile app. The results suggest that there exists a complementary interdependence between these media, as having subscribed to one of them decreases the hazard of canceling a parallel subscription to the other one. This holds true for nearly all customers. Accordingly, we find that the mobile app increases the lifetimes and lifetime values of print customers and vice versa. We also analyze the attribution of these effects.
\end{abstract}

Keywords Mobile apps $\cdot$ Print media $\cdot$ News $\cdot$ Substitution . Complementarity $\cdot$ Customer lifetime value $\cdot$ Survival analysis

\section{JEL classifications M31}

\section{Introduction}

The term "mediamorphosis" has been coined for the everchanging media economy, which suggests that incumbent media have to adapt when new media become relevant for

Responsible Editors: Thomas Hess and Hans-Dieter Zimmermann

Paul Alpar

alpar@wiwi.uni-marburg.de

1 School of Business and Economics, University at Marburg, Universitätsstr. 24, 35037 Marburg, Germany customers (Fidler 1997). This is because the presence of new media may change the customer-publisher relationship, affecting its duration as well as its monetary value to the publisher (Hennig-Thurau et al. 2010).

During the last two decades, the media industry faced two such disruptions. The first occurred in the mid-1990s and was triggered by the diffusion of the Internet. Publishers started to experiment with the new possibility of distributing content online in order to reach a new audience and not to lose their existing customers to competitors. Possibly unintended, this led to a dramatic change in media consumption behavior: Customers soon became accustomed to the opportunity of accessing content at any time and largely free of cost. This, in turn, forced publishers to increase their investments in the online channel. However, this channel did not give them much competitive advantage but quickly became a necessity to avoid competitive disadvantage. At the same time, the offline channel suffered from the rise of the Internet, as it was less used. In the case of news, for example, many customers switched from reading printed newspapers to Internet information sources. This problem was exacerbated by the fact that new Internet applications often specialized on classifieds (such as jobs, used cars, or dating) and took most of this market from newspapers. Besides, advertisers recognized that some customers can better (or only) be reached via the Internet and that ads in this channel can be better targeted and monitored than ads in the offline channel. For these reasons, traditional publishers soon experienced losses in advertising revenues as well. A number of print products disappeared; some publishers transferred their content to the Internet as an additional or exclusive content delivery channel, while others acquired the new online competitors.

While the Internet enabled any-time access to content, customers were still bound to certain access points, that is, stationary Internet connections (e.g., their office desk), complemented by Wi-Fi connections at other fixed points. 
Soon, the demand to overcome this restriction emerged. It was met by extending the functionality of mobile phones to media consumption. This led to the second disruption in the media industry, as publishers saw the need to deliver content in a form suitable for the new devices. In the beginning, they had to adjust their websites for this purpose, since these had originally not been designed for small screens, low resolutions, and small input keys. When mobile phones became "smart", however, the possibility to install applications (apps) on them created an alternative for distributing mobile content independently of websites. In addition, tablets emerged on the market as another type of end device suited for surfing on the Internet or running apps. The number of end devices suitable for mobile content delivery meanwhile surpassed the number of PCs. This, again, increased the number of potential customers and their sense of urgency and need for consumption everywhere and anytime. The second disruption has forced publishers to invest further while the monetization of content remains a problem.

Resulting from these disruptions, customers nowadays can choose among three channels for consuming content: offline, online, and mobile. This decision is not exclusive; that is, they may also use more than one channel. Publishers need to determine whether it is economical to meet this demand and to serve each channel. Setting up, maintaining, and serving a channel is expensive, but it may bring additional revenues due to new customers who would not have consumed content using another channel. Furthermore, the presence of a new channel may also affect the behavior of existing customers: On one hand, it is possible that some of them consume content using the new channel complementarily to a channel they have used before. This may increase their value to the publisher and prevent them from switching to competitors. On the other hand, some existing customers may substitute a channel they have used before with the new one, so that the latter may cannibalize revenues. The total effect of this substitution depends on the different profitabilities of the channels.

In an earlier version of this paper (Winter et al. 2016), we have investigated the decision of a publisher who already serves the offline channel to also serve the mobile channel. More concretely, we have examined whether a mobile app can "defend" print media in that it prevents existing subscribers from canceling their subscription, that is, whether it can prolong their customer lifetime (CL). In our analysis, we have assumed all customers to be homogeneous with regard to how they react to the introduction of the mobile app. Previous research suggests, however, that media consumption behavior may be heterogeneous across customers, as will be reviewed below. In this paper, we, therefore, extend our approach by exploring whether such differences across customers exist. We also evaluate how changes in the CL translate to changes in the customer lifetime value (CLV). In summary, we develop a model that reveals the value of the individual channels to a publisher as well as their interdependence and its impact for different customers based on empirical subscription cancelation data.

We apply our model to the case of a respected newspaper, as newspapers in their traditional, printed form are typical representatives of print media. Note that we will use the term "newspaper" in the following to refer to a product that contains news augmented by background information, opinions, letters by readers, puzzles, and so on, independently of the medium through which it is consumed. This is in order to differentiate it from "naked" news, as delivered by some news agencies, or, for example, posts by individuals on Twitter.

The remainder of this paper is structured as follows. Next, we review literature related to our work. Afterwards, we develop our model. Its application is described in section "Application and dataset". The results are presented and discussed in section "Results and discussion". Section "Conclusions" concludes this paper with remarks on generalizability, implications, and limitations.

\section{Related research}

Broadly, this paper contributes to three streams of research: first, to research that investigates the relationship between different content delivery channels, second, to research that explores differences in media consumption behavior across customers, and third, to research of customer lifetime values. We will review these three streams in the following. A particular focus is given to the news industry, as it is the field of application for our model and has been analyzed in many previous studies.

\section{Relationship between content delivery channels}

After the first disruption in the media industry due to the advent of the Internet, research has started to investigate the relationship between the online and the offline channel. For example, Althaus and Tewksbury (2000) have conducted a survey on news consumption behavior among students. They have found that the reported time spent for consuming news online is positively associated with the reported time spent for reading newspapers, which indicates a complementary relationship between these media, but not with the reported time spent for watching news on television. In a comparable approach, Chan (2005) has come to similar conclusions. In contrast, Simon and Kadiyali (2007) have found that the number of sales of a print magazine decreases when it offers free content online. This suggests a substitutive relationship between these channels, which the authors have shown to be moderated by the degree of overlap between content. Some of these results may be transferrable to the mobile channel, but due its special characteristics (such as the portability of mobile 
devices), this should not be assumed without explicit research (e.g., Shankar and Balasubramanian 2009).

In fact, a new branch of research that analyzes the relationship between the online and the mobile channel has emerged after the second disruption in the media industry. For example, Bang et al. (2013) have compared the suitability of these channels for product selling. Their results suggest that whether the relationship between the channels is complementary or substitutive depends on the time criticality and the information intensity of the product. Chyi and Chadha (2012) have found in a survey that there is a complementary relationship between consuming news using a stationary PC and consuming news using a mobile device. They have argued that the fit of a device with what is desirable for news consumption is a determinant of its usage for this purpose. This may also apply to mobile apps. Böhmer et al. (2011) have identified the context of consumers (such as their location and the time of the day) to be a further factor influencing mobile app usage.

Most closely related to this paper are studies that have investigated the relationship between the offline and the mobile channel. Elangovan and Gupta (2015) have considered this relationship from a technology acceptance perspective. Their results suggest that the dissonance between attitudes toward offline and mobile news consumption is a predictor of the intention to use a mobile news app. Westlund and Färdigh (2015) have found that many people consume news using rather a single channel than several ones and that there is a shift in this usage from the offline toward the mobile channel (and/or the online channel). This indicates a substitution.

To summarize, research is not unanimous about the relationship between content delivery channels. Many studies in this area have relied on surveys. Such data are mostly subjective and, thus, usually less accurate than actual performance data (e.g., Bertrand and Mullainathan 2001). Furthermore, while indications for channel interdependence have been found, few authors have aimed at capturing this interdependence in a model. Without a model, however, it can hardly be quantified and the influence of covariates can hardly be controlled for. We address these gaps by a model that is able to capture and quantify channel interdependence from subscription cancelation data.

\section{Customer heterogeneity in media consumption behavior}

Age, gender, income, and education have been considered as the main individual characteristics that may be associated with the choice of a channel for news consumption. Thorson et al. (2015) have compared newspapers and mobile apps in a contingency model to explain how individual characteristics influence channel choice. Analyzing secondary survey data, they have found that these characteristics, especially age, can be a moderator of whether the offline and the mobile channel complement or substitute each other. Chan (2015) has conducted a survey in Hong Kong to analyze whether age cohort differences exist with respect to use of mobile news and other channels. He has found that the cohort 18-34 uses the mobile channel most, after TV but before print or other digital channels. For the 35-54 cohort, mobile news comes in fourth, but these people are almost as often multiplatform users as the youngest cohort. The oldest cohort, 55-70, mainly consumes news through TV and print. Westlund and Färdigh (2015) have also compared three age cohorts (though not with the same cohort definitions) based on surveys in Sweden from 1986 to 2012. They have determined that the oldest cohort is still mostly using print (and embracing online over time), the middle cohort mostly uses online (adding mobile over time), and the youngest cohort uses online and mobile with a strong increase in mobile. There are studies that show that more education (De Waal and Schoenbach 2010), higher incomes, and male gender (Edmonds et al. 2013) lead to more use of print media. However, such results have not been presented (yet) for the mobile channel or in the context of the possible switching behavior between the two channels. The latter aspect, impact on channel relationship, is little analyzed so far. For example, it can be expected that customers with high income will adopt a mobile version of a newspaper more quickly than those with a lower income because they can easily afford the necessary devices and Internet connections. However, they may not substitute the old channel by the new one as quick as lower income customers may because they can also afford both. Thus, it is interesting to analyze whether the research results can be confirmed for age and to determine whether channel relationship is moderated by the other individual characteristics.

\section{Lifetime value view on customers}

The lifetime value view on customers is not new for newspaper publishing. For example, Keane and Wang (1995) have used CLVs to segment customers for improving advertising and circulation figures of newspapers. They have demonstrated that the lifetime value model is appropriate to investigate the impact of customer retention (i.e., prolonging a customer's lifetime) on a publisher's profits. The link between CLs and CLVs is theoretically well-established (see, e.g., Anderson and Mittal 2000) and has been confirmed in many empirical studies (e.g., Gupta et al. 2004).

Against this background, a new content delivery channel can affect profits in (at least) two ways: On one hand, it may contribute to customer retention; e.g., Boehm (2008) has shown that bank customers who use online banking (i.e., the online channel) have a longer CL than those who use only the 
offline channel. On the other hand, the new channel may be different from the traditional ones in terms of profitability (and, thus, CLVs); e.g., Gensler et al. (2012) have found that bank customers generate more revenue and can be served with less cost if they use online banking. In analogy, it may be desirable for publishers to migrate their customers to other channels (see also Ansari et al. 2008).

It has often been stressed that it is important to account for potential differences between channels when calculating CLVs. This is, on one hand, in order to understand where profits come from (Neslin and Shankar 2009) but, on the other hand, also in order to avoid customer heterogeneity regarding channel choice being a source of serious bias (Fader and Hardie 2010). In particular, many studies have suggested that customers who use several channels have a different value to a publisher than customers who use only a single channel (e.g., Kumar and Venkatesan 2005).

To summarize, previous research has confirmed that customers' channel choice can have a significant impact on the profits of a publisher. It has also been demonstrated that this impact can be measured by CLVs and their antecedents, the CLs. We contribute to this stream of research by analyzing the effects a mobile app has on the CLs and CLVs of customers of print media, and vice versa. While the perceived (added) value of a mobile app from the customers' perspective has already been a topic in previous research, the publishers' perspective has not been sufficiently investigated yet.

\section{Model}

We now present a survival analysis-based model with which the CL and the CLV of a customer $i$ at a certain point in time $t_{0}$ (normalized to $t_{0}=0$ ) can be quantified from her subscriptions to up to two content delivery channels. We index these channels by $j \in\{1 ; 2\}$, where in our context $j=1$ means the offline channel and $j=2$ means the mobile channel.

\section{Structural model}

The central component of our model is the probability $S_{i, j}(t)$ that $i$ will retain a subscription that is active in $t_{0}$ for at least $t$ time units in the future (that is, up to the point in time $t$ ). Formally, we define define $S_{i, j}(t):=P\left[T_{i, j}^{\mathrm{end}} \geq t \mid T_{i, j}^{\mathrm{end}} \geq 0\right]$ for $T_{i, j}^{\text {end }} \geq 0$, where $T_{i, j}^{\text {end }}$ is a random variable that represents the point in time at which the subscription ends. For convenience of notation, we define $S_{i, j}(t):=0$ for the cases that $i$ had a subscription to $j$ but canceled it before $t_{0}\left(-\infty<T_{i, j}^{\text {end }}<0\right)$ or that she never had a subscription to $j\left(T_{i, j}^{\text {end }}=-\infty\right)$. In a time-discrete context, which is advised for modeling subscriptions (Schmittlein et al. 1987), $S_{i, j}(t)$ can for $T_{i, j}^{\mathrm{end}} \geq 0$ be expressed as

$S_{i, j}(t)=\prod_{t^{\prime}=1}^{t}\left(1-h_{i, j}\left(t^{\prime}-1\right)\right)$

Here, $h_{i, j}(t)$ denotes the hazard of $i$ canceling her subscription to $j$ at (the end of) $t$, given that she has not done so before; formally, $h_{i, j}(t):=P\left[T_{i, j}^{\mathrm{end}}=t \mid T_{i, j}^{\mathrm{end}} \geq t\right]$. This hazard, which often is also referred to as the churn rate, is a crucial element in the calculation of the CLV because it is the only element that describes actual customer behavior. A customer's decision to cancel a subscription may depend on various factors, which we will investigate below. However, one factor needs special consideration: It may be (and is, as argued earlier, likely) that the decision of $i$ to cancel a subscription to $j$ is influenced by whether she has a parallel subscription to the other channel $j$ at $t$. Formally, $h_{i, j}(t)$ may in this case take a value $h_{i, j}^{2}$ that is different from the value $h_{i, j}^{1}$ that it takes when the subscription to $j$ is the only active one at $t$. It is important to account for this potential dependency in order to avoid biases. This can be done by calculating $h_{i, j}(t)$ as

$h_{i, j}(t)=\left(1-S_{i, j^{\prime}}^{2}(t)\right) \cdot h_{i, j}^{1}+S_{i, j}^{2}(t) \cdot h_{i, j}^{2}$

where $S_{i, j}^{2}(t)=\prod_{t^{\prime}=1}^{t}\left(1-h_{i, j}^{2}\right)$. The explanation for (2) is that if $i$ has an active subscription to $j$ at $t_{0}$, it cannot be foreseen whether she will have canceled it up to $t$ or not. Therefore, $h_{i, j}^{1}$ and $h_{i, j}^{2}$ need both to be considered and to be weighted by the probabilities of the respective cases. By definition, $h_{i, j}(t)$ is calculated based on the assumption that $T_{i, j}^{\text {end }} \geq t$, i.e., that $i$ has not canceled her subscription to $j$ up to $t$. The probability of her also not having canceled her subscription to $j^{\prime}$ is, therefore, not given by $S_{i, j^{\prime}}(t)$ but by a similar function $S_{i, j}^{2}(t)$ that accounts for the knowledge that $h_{i, j^{\prime}}^{2}$ has been the factual cancelation hazard since $t_{0}$.

Assuming for the moment that $h_{i, j}^{1}$ and $h_{i, j}^{2}$ are given, we can calculate the expected remaining lifetime $S L_{i, j}:=E\left[T_{i, j}^{\mathrm{end}} \mid T_{i, j}^{\mathrm{end}} \geq 0\right]$ that a subscription has in $t_{0}$ (see, e.g., Misra 1992, p. 180 ff.):

$S L_{i, j}=\sum_{t=1}^{\infty} S_{i, j}(t)$

Its expected remaining lifetime value $\left(S L V_{i, j}\right)$ results, in principal, from weighting $S L_{i, j}$ by the value $v_{i, j}$ it generates per time unit to the publisher. $v_{i, j}$ can usually be expressed in terms of profits, i.e., $v_{i, j}=m_{j} \cdot p_{i, j}$, where $p_{i, j}$ is the price that $i$ pays at each point in time $t$ (which we assume to happen at the beginning of $t$ ) and $m_{j}$ is the publisher's profit margin. 
However, these future profits need to be discounted to account for the publisher's time preference. Representing this preference by a discount rate $r, S L V_{i, j}$ can be calculated as follows (e.g., Berger and Nasr 1998):

$S L V_{i, j}=\sum_{t=1}^{\infty} \frac{S_{i, j}(t) \cdot v_{i, j}}{(1+r)^{t}}$.

So far, we have considered the lifetime and the lifetime value of a subscription, while we are rather interested in the lifetime and the lifetime value of a customer. The customerlevel figures can be defined as an aggregation of the subscription-level ones. For the CL of $i\left(C L_{i}\right)$, we use the aggregation

$C L_{i}:=\max \left(S L_{i, j} ; S L_{i, j^{\prime}}\right)$.

That is, we define the lifetime of a customer as the maximum of the expected lifetimes of her subscriptions. Note that this does not equal the expected maximum lifetime of her subscriptions, which would be an alternative definition. Both definitions describe the total duration of the customer's relationship to the publisher regarding the two focal channels.

Finally, the CLV of $i\left(C L V_{i}\right)$ can, in principal, be calculated by summing the lifetime values of all her subscriptions. ${ }^{1}$ However, customers often get a discount when they have subscriptions to several channels. This discount reduces the publisher's profit and, thus, the CLVs, so that it has to be subtracted from the sum of the subscription lifetime values. $i$ gets a discount $\left(d_{i}\right)$ in $t$ only if her subscriptions to $j$ and $j^{\prime}$ (if applicable) are both still active by then, which happens with the probability $S_{i, j}^{2}(t) \cdot S_{i, j^{\prime}}^{2}(t)$. Therefore, after accumulating the expected discount over time, $C L V_{i}$ is given by

$C L V_{i}:=S L V_{i, j}+S L V_{i, j^{\prime}}-\sum_{t=1}^{\infty} \frac{S_{i, j}^{2}(t) \cdot S_{i, j}^{2}(t) \cdot d_{i}}{(1+r)^{t}}$.

Similar definitions of the CLV have been used in previous research (e.g., Donkers et al. 2007).

Note that our concept of subscription and customer lifetimes and lifetime values is a purely residual one. That is, we have defined these values on the basis of the expected future behavior of existing customers, ignoring their behavior up to $t_{0}$, as it is not relevant anymore for decisions at $t_{0}$ and later. This is a common view in the literature on the CLV (e.g., Kumar and Reinartz 2012, p. 305).

\footnotetext{
${ }^{1}$ Note that if $i$ has no active subscription for $j^{\prime}$ in $t_{0}, S_{i, j^{\prime}}(t)=0$ for all $t$. This implies $S L_{i, j^{\prime}}=0$ and, thus, $S L V_{i, j^{\prime}}=0$. Therefore, $C L_{i}$ and $C L V_{i}$ collapse to $S L_{i, j}$ and $S L V_{i, j}$, respectively.
}

\section{Measurement model}

To complete our model, we have to specify the formation of the hazard values $h_{i, j}^{1}$ and $h_{i, j}^{2}$. They can be derived from empirical data, as these contain the corresponding latent utilities $U_{i, j}^{1}$ and $U_{i, j}^{2}$ that a customer experiences when she cancels a subscription. We model the relationship between $h_{i, j}^{J}$ and $U_{i, j}^{J}$ for $J \in\{1 ; 2\}$ by a logit-formed link function (Iliescu et al. 2008 have also used this function to model cancelation hazards); that is,

$h_{i, j}^{J}=\frac{\exp \left(U_{i, j}^{J}\right)}{1+\exp \left(U_{i, j}^{J}\right)}$.

For the latent utility $U_{i, j}^{1}$ of canceling a subscription to one channel in the absence of a parallel subscription to the other channel, we use the model

$$
\begin{aligned}
U_{i, j}^{1}= & \beta_{0, j}+\beta_{1, j} \cdot \text { Duration }_{i, j}+\beta_{2, j} \cdot\left(1-\text { Individual }_{i}\right) \\
& +\left(\beta_{3, j} \cdot \text { Income }_{i}+\beta_{4, j} \cdot \text { Age }_{i}+\beta_{5, j} \cdot \text { Gender }_{i}\right) \\
& \cdot \text { Individual }_{i} .
\end{aligned}
$$

This is motivated by the following considerations: First, one aim of this study is to investigate the differences between the offline and the mobile channel. Therefore, we use separate intercepts $\left(\beta_{0,1}\right.$ and $\left.\beta_{0,2}\right)$ for $U_{i, 1}^{1}$ and $U_{i, 2}^{1}$. An essentially equivalent approach would be to use a common intercept and to include a dummy variable that describes which channel is modeled. We also let the coefficients of the independent variables differ between channels in order to recognize potential differences in the influence of these variables.

Next, we expect the total duration of a subscription from the point in time at which it started $\left(t_{i, j}^{\text {start }}\right)$ up to $t_{0}$, Duration $_{i, j}=-t_{i, j}^{\text {start }}$, to influence the cancelation hazard. The direction of this influence, however, is unclear. On one hand, one may assume that long-time customers are less likely to cancel their subscription(s) because they are more accustomed to consuming the publisher's content (e.g., Bolton 1998). Furthermore, compared to rather new customers, they can be assumed to have more thoroughly evaluated the content (e.g., in terms of quality), so that their expectations are more likely to be met. On the other hand, customers may lose their interest in the content over time or find competitive publishers who suit their needs better (e.g., Zeelenberg and Pieters 2004).

We also account for customer heterogeneity since different customers may cancel their subscription(s) with different probabilities. For this purpose, we include various customer characteristics in (8). First, not only individuals but also organizations (such as companies, universities, associations, etc.) 
can subscribe to a publisher's content, so that we include a dummy variable (Individual ${ }_{i}$ ) to control for differences between the former (Individual ${ }_{i}=1$ ) and the latter Individual $\left._{i}=0\right)$ group. Such differences are reflected in the coefficients $\beta_{2, j}$, while $\beta_{3, j}, \beta_{4, j}$, and $\beta_{5, j}$ capture differences within the group of individuals. Concretely, we control for an individual's age at $t_{0}\left(\right.$ Age $\left._{i}\right)$, gender $\left(\right.$ Gender $_{i}=0$ for men and Gender $_{i}=1$ for women), and income $\left(\right.$ Income $\left._{i}\right)$. The equation does not contain education as a variable because corresponding data are missing in the dataset we use (see below).

Now that we have specified possible determinants of the decision to cancel a subscription to one channel, we aim to investigate how this decision is influenced by the presence of a parallel subscription to the other channel. To capture this influence, we decompose the corresponding latent utility $U_{i, j}^{2}$ into an intrinsic component, which equals $U_{i, j}^{1}$, and an extrinsic component $\gamma_{i, j}$ :

$U_{i, j}^{2}=U_{i, j}^{1}+\gamma_{i, j}$

A similar approach has been developed in previous research to model the interdependence between two different types of search engine results (Yang and Ghose 2010). It can be interpreted as follows: $\gamma_{i, j}$ measures the influence of channel $j$ on channel $j$, which may be different from the reverse effect, for customer $i$. If $\gamma_{i, j}$ is zero, $j$ has no influence on $j$ : The latent utility of canceling a subscription to $j$ in the presence of a parallel subscription to $j$ is the same as if the subscription to $j$ were the only active one $\left(U_{i, j}^{2}=U_{i, j}^{1}\right)$. If $\gamma_{i, j}$ differs significantly from zero, however, an influence of $j$ on $j$ exists, as $U_{i, j}^{2} \neq U_{i, j}^{1}$. A positive value of $\gamma_{i, j}$ indicates a substitutive influence: A parallel subscription to $j$ increases the hazard that $i$ cancels a subscription to $j$. Contrarily, a negative value of $\gamma_{i, j}$ means that a parallel subscription to $j$ decreases the hazard of canceling a subscription to $j$, indicating a complementary influence.

In the abovementioned previous version of this paper (Winter et al. 2016), we have assumed $\gamma_{i, j}$ to be constant across all customers. Here, we account for the possibility that different (groups of) customers may react differently to the introduction of a new content delivery channel by modeling $\gamma_{i, j}$ as follows:

$\gamma_{i, j}=\delta_{0, j}+\delta_{1} \cdot$ TimeAsCustomer $_{i}+\delta_{2} \cdot\left(1-\right.$ Individual $\left._{i}\right)+\left(\delta_{3} \cdot\right.$ Income $_{i}+\delta_{4} \cdot$ Age $_{i}+\delta_{5} \cdot$ Gender $\left._{i}\right) \cdot$ Individual $_{i}$

This model is motivated by the following considerations: With regard to the usual customer demographics, differences in news consumption behavior have already been found by previous research, as described above. We use the same customer characteristics as in (8). Organizations (which do not exhibit such characteristics) are also treated the same way as it was done in (8). Finally, we want to investigate potential differences among customers based on how long their relationship to the publisher already exists. Therefore, we have included the time span between their first (still existing) subscription, regardless for which channel it was, to $t_{0}$ (TimeAsCustomer $_{i}$ ) as another potential determinant of $\gamma_{i, j}$. Note that we allow the intercept $\left(\delta_{0, j}\right)$ in $(10)$ to differ between the two channels, by which we account for the fact that the offline channel may exhibit a different baseline influence on the mobile channel than vice versa.

\section{Comments on estimation}

We estimate our model by maximum likelihood, using the BFGS algorithm (Broyden 1970; Fletcher 1970; Goldfarb 1970; Shanno 1970). As we will explain below, the data to which we intend to apply our model describe (the transition between) only two points in time. In this case, the likelihood function of our model is essentially the same as for a standard logit model. When (transitions between) more than two points in time are analyzed, estimation is more difficult due to the time-varying cancelation hazard as specified in (2). However, this situation can be reduced to the one that we consider; see (Therneau et al. 2017) for details.

For the calculation of $S L_{i, j}, S L V_{i, j}$, and the accumulated discount in (6), we sum over a horizon of 1200 points in time (corresponding to 100 years for our dataset), as we cannot sum to infinity in practice. As it is to be expected, none of these values changes notably when a larger horizon is used, reflecting that hardly any customer retains a subscription for such a long time after $t_{0}$.

\section{Application and dataset}

We now apply our model to a dataset that we have received from a publisher of a respected national German daily newspaper. Due to a confidentiality agreement, we can neither identify this publisher nor describe it in much detail. The newspaper appeals to a general audience, as it covers all common subject areas: politics, finance, culture, sports, and so on. It is published in three delivery channels: offline, online, and mobile. In the offline channel, it appears in a print version, which enjoys a large subscriber base. In the online channel, 
articles are published on a website. However, in order not to cannibalize subscribers to the print version, these articles are usually shorter and less elaborated. Furthermore, they are surrounded by different forms of advertisement. There also exists an exact copy of the print version for the Internet that requires a payment. In the mobile channel, the publisher offers a mobile-enabled website and several mobile apps. One of the latter allows customers to read the exact copy of the print version on their mobile devices. It includes a few additional ads and has some suitable features such as an automatic search for articles that contain user-specified keywords. While it can be downloaded for free, it can only be used with a paid subscription. We choose the print version and this mobile app for our analysis of interdependence between the offline and the mobile channel. This is, on one hand, because these media are typical representatives of the respective channels and, on the other hand, because they are perfect substitutes in terms of content, so that there are no differences in content that could influence the results.

The publisher offers different subscription models for both, the offline and the mobile channel. For better comparability, we consider only one of these models and choose one that is available for both channels. The chosen subscription model is the one that is selected most frequently by customers. Pricing is similar but not identical between channels: The subscription to the mobile channel is slightly cheaper than the one to the offline channel. Customers who subscribe to both channels receive a significant discount. They can cancel each channel independently of the other but lose the (future) discount in this case. The publisher's profit margin after subtracting the costs of distribution is much higher for the mobile channel than for the offline channel, as it is to be expected.

Our dataset contains data on the subscriptions to the focal channels and on the customers who hold these subscriptions (age and gender). It is a "snapshot" of the publisher's database at a single day (September 04, 2015), which corresponds to $t_{0}$. Importantly, it contains only data on subscriptions that still have been active at $t_{0}$. This makes it difficult to reliably analyze subscription behavior, as the absence of historical subscriptions that have been canceled before $t_{0}$ could bias the results. The analysis of subscription cancelation behavior at and beyond $t_{0}$ (which we carry out in this paper), however, is not biased by this truncation (as long as the cancelation hazard does not change over calendar time).

Obviously, one can hardly judge from a snapshot of all active subscriptions which will be canceled in the future. However, some of them already carry an end date. This can happen for (at least) two reasons. Fist, some customers may have actively canceled an unlimited subscription, whereupon the date of last delivery (after a cancelation period) is saved in the database. Others may not have extended a fixed-term subscription that ends at the indicated time up to $t_{0}$. Our data do not allow us to distinguish these cases. Besides, the latter case carries the chance that such customers will eventually extend their subscription. Therefore, we choose a relatively short interval of one month between $t_{0}$ and the next point in time $t_{1}$ and consider such subscriptions as ended that are planned to end up to then.

We have conducted some pre-processing of our dataset before analysis. First, we have augmented it by the (proprietary) buying power index (BPI) obtained from a market research company (GfK 2016) as a surrogate for income, which was missing in the data. It was assigned to each customer based on her address. Second, we have excluded all customers who live outside of Germany. This was in order to reduce the influence of potential cultural differences, which we do not investigate in this paper. We have also excluded all customers who have more than one subscription to the same channel. This can happen, for example, when organizations purchase subscriptions for each of their employees, which is not representative of "usual" customer behavior. Third, for customers who have not provided their age, we have imputed it based on a linear regression on their gender and their buying power index. We cannot reveal the exact numbers of customers or subscriptions that have remained in our dataset after pre-processing due to confidentiality, but both numbers are in the six-figure range, so that no statistical problems are to be expected even for seldom-observed combinations of the qualitative variables. The characteristics of the pre-processed dataset are summarized in Tables 1 and 2.

Some statistics are particularly noteworthy. First, women are obviously under-represented in our dataset (compared to the German population). A possible explanation is that often only one member of a family holds a subscription, but the content is shared with the other members of the household. This usually is the main earner, who in Germany is mostly a man (Destatis 2016). Second, only comparatively few customers have subscribed to both channels; the average number of subscriptions per customer is 1.02 (which still suffices for statistical purposes). Third, the mean duration of a subscription to the mobile channel is low compared to its equivalent for the offline channel. This simply results from the fact that the former has been established just a few years ago, while the latter has been served for several decades.

\section{Results and discussion}

\section{Measurement model}

Table 3 shows the results of our estimations with regard to what determines the decision to cancel a single subscription. We have mean-centered all quantitative variables, so that the 
Table 1 Overview of customers in our dataset

\begin{tabular}{|c|c|c|c|c|c|c|}
\hline \multirow{2}{*}{$\begin{array}{l}\text { Group } \\
\text { Subscription(s) }\end{array}$} & \multicolumn{4}{|c|}{ Individuals } & \multirow[t]{2}{*}{ Organizations } & \multirow[t]{2}{*}{ Total } \\
\hline & Men & & Women & & & \\
\hline Only offline & $59.62 \%$ & & $19.40 \%$ & & $12.63 \%$ & $91.65 \%$ \\
\hline Only mobile & $4.39 \%$ & & $0.99 \%$ & & $0.82 \%$ & $6.20 \%$ \\
\hline Both & $1.29 \%$ & & $0.30 \%$ & & $0.56 \%$ & $2.14 \%$ \\
\hline Total & $65.30 \%$ & & $20.68 \%$ & & $14.01 \%$ & $100 \%$ \\
\hline $\begin{array}{l}\text { Other characteristics } \\
\text { Age (in years) }\end{array}$ & $\begin{array}{l}\text { Mean } \\
\quad 63.11\end{array}$ & $\begin{array}{l}\text { Std. dev. } \\
17.87\end{array}$ & $\begin{array}{l}\text { Mean } \\
56.68\end{array}$ & $\begin{array}{l}\text { Std. dev. } \\
20.13\end{array}$ & & \\
\hline Income (BPI) & 106.06 & 16.49 & 107.15 & 17.59 & & \\
\hline
\end{tabular}

intercepts give the mean effect for the reference customer: a male individual of average age and with average income who has subscribed to the respective channel an average time ago. For the other coefficients, a positive (negative) sign indicates an increase (decrease) in the cancelation hazard, corresponding to a decrease (increase) in the remaining lifetime and lifetime value of a subscription.

The results show that longer-lasting subscriptions are canceled less often than shorter-lasting ones and that organizations cancel their subscriptions less likely than individuals. These findings hold true for both channels. Regarding consumer heterogeneity, the channels differ. While no significant differences in cancelation behavior are found between men and women of different ages for the mobile channel, some differences exist for the offline channel. More concretely, older customers are found to cancel their subscription to the offline channel (their offline subscription) less likely than younger ones. This is consistent with results from previous research suggesting that old people stick to their accustomed news consumption behavior rather than to change it (Chan 2015). Furthermore, women are found to cancel their offline subscription more likely than men. This may again be explained by the fact that it usually is a man who holds a subscription in a family, so that women cancel theirs, e.g., when they marry. Differences among individuals who have subscribed to the mobile channel only exist with regard to the BPI: Individuals from richer regions cancel their subscription more likely than individuals from poorer regions. No corresponding effect is found for the offline channel. A potential interpretation of these findings will be given below.

Table 4 shows our results on how the two channels influence each other. The main result here is that the intercept for the offline channel $\left(\delta_{0,1}\right)$ is significant, which means that the mobile channel has an influence on the offline channel. As $\delta_{0,1}$ is negative, this influence is complementary: The hazard of canceling an offline subscription is significantly reduced for customers who have a parallel subscription to the mobile channel (a mobile subscription). For an average customer, this reduction is from $1.26 \%$ to $0.92 \%(-27.10 \%)$. We define an average customer as one who is a man, a woman, or an organization with respective probabilities derived from the relative frequencies given in Table 1, with mean values for all quantitative variables. Interestingly, we also find evidence for a complementary effect of the offline channel on the mobile channel, as $\delta_{0,2}$ is as well significant and negative: Having a parallel offline subscription reduces the hazard to cancel a mobile subscription from $1.22 \%$ to $0.27 \%(-77.87 \%)$.

A possible explanation for this mutual complementarity stems from the niche theory (Dimmick et al. 2004): Many customers read printed newspapers when they are at home, but they may prefer to consume the content via a mobile app when they are in a situation unsuitable for printed newspapers (e.g., when they travel in a crowded bus). The two niches complement each other, as the new niche allows for additional situational spaces for news access (Westlund and Färdigh 2011). This is supported by the aforementioned findings that mobile app usage depends on the context (Böhmer et al. 2011)
Table 2 Overview of subscriptions in our dataset

\begin{tabular}{|c|c|c|c|c|c|}
\hline $\begin{array}{l}\text { Channel } \\
\text { Status }\end{array}$ & Offline & & Mobile & & Total \\
\hline Active up to $t_{1}$ & $89.44 \%$ & & $8.04 \%$ & & $97.48 \%$ \\
\hline Ended before $t_{1}$ & $2.39 \%$ & & $0.14 \%$ & & $2.52 \%$ \\
\hline Total & $91.83 \%$ & & $8.17 \%$ & & $100 \%$ \\
\hline Other characteristics & Mean & Std. dev. & Mean & Std. dev. & \\
\hline Duration up to $t_{0}$ (in months) & 70.37 & 94.20 & 18.82 & 7.83 & \\
\hline
\end{tabular}


Table 3 Determinants of the hazard of canceling a single subscription

\begin{tabular}{|c|c|c|c|c|c|c|}
\hline \multirow{3}{*}{$\begin{array}{l}\text { Variable } \\
\text { (Intercept) }\end{array}$} & \multicolumn{3}{|c|}{ Offline channel } & \multicolumn{3}{|c|}{ Mobile channel } \\
\hline & Coef. & Std. err. & $\mathrm{p}$ & Coef. & Std. err. & $\mathrm{p}$ \\
\hline & -4.3384 & 0.0412 & $<0.0001 * * *$ & -4.2694 & 0.1290 & $<0.0001 * * *$ \\
\hline & & & $<0.0001 * * *$ & & & \\
\hline Duration & -0.0190 & 0.0007 & & -0.1131 & 0.0103 & $<0.0001 * * * *$ \\
\hline 1-Individual & -0.2681 & 0.0695 & $0.0001 * * *$ & -1.8047 & 0.4884 & $0.0002 * * *$ \\
\hline Individual x Income (BPI) & -0.0017 & 0.0012 & 0.1570 & +0.0123 & 0.0040 & $0.0020 * *$ \\
\hline Individual x Age & -0.0194 & 0.0012 & $<0.0001 * * *$ & -0.0061 & 0.0057 & 0.2901 \\
\hline Individual x Gender & +0.3160 & 0.0435 & $<0.0001 * * *$ & +0.1984 & 0.1748 & 0.2564 \\
\hline \multicolumn{7}{|c|}{ Pseudo- $R^{2}$ (Nagelkerke 1991): $9.35 \%$. Significance is as follows: } \\
\hline \multicolumn{7}{|l|}{$* p<0.05$} \\
\hline \multicolumn{7}{|l|}{$* * p<0.01$} \\
\hline$* * * p<0.001$ & & & & & & \\
\hline
\end{tabular}

and may explain why the relationship between these media is not substitutive. Now, if the customers are satisfied after having used one of them (e.g., because their information need has been fulfilled), this may increase their likelihood to keep the other one, as satisfaction is a key determinant of customer retention (Anderson and Mittal 2000). Thus, both media are complementary to each other.

While the intercepts indicate channel complementarity for the reference customer (see above), the remaining coefficients inform about whether this complementarity also exists for other customers, that is, how customer heterogeneity influences the channel relationship. They show that the average result generalizes to most customers, regardless of whether they have a long-lasting or a short-lasting relationship with the publisher, whether they are individuals or organizations, and whether they are men or women. Also, we do not find significant differences between older and younger customers. The latter result is especially interesting because it seems to contradict the abovementioned results of previous research, which suggest

Table 4 Determinants of the mutual influence of the two channels

\begin{tabular}{llll}
\hline Variable & Coef. & Std. err. & $\mathrm{p}$ \\
\hline (Intercept for offline channel) & -0.5383 & 0.2540 & $0.0341 *$ \\
(Intercept for mobile channel) & -1.6427 & 0.4087 & 0.0001 *** \\
TimeAsCustomer & +0.0033 & 0.0028 & 0.2369 \\
1-Individual & -0.0441 & 0.4512 & 0.9222 \\
Individual x Income (BPI) & -0.0308 & 0.0131 & $0.0186 *$ \\
Individual x Age & +0.0046 & 0.0110 & 0.6765 \\
Individual x Gender & -0.4425 & 0.4234 & 0.2960 \\
\hline
\end{tabular}

A negative coefficient indicates an increase in channel complementarity. Significance is as follows:

$* p<0.05$

$* * p<0.01$

$* * * p<0.001$ that age is a moderator of the type of channel relationship (Chan et al. 2015, Thorson et al. 2015). A potential explanation for this is that age is (only) a determinant of canceling each individual subscription (or a single subscription), which our results have confirmed at least for the offline channel (see above). This emphasizes the need to isolate effects of variables on the individual cancelation hazards on one hand and the channel relationship on the other hand. Of course, it should also not be forgotten that the results of previous research were derived from survey data, which means that they reflect reported rather than actual media consumption behavior.

The only variable that we find to be a significant determinant of the channel relationship is the customers' BPI: The richer the region is where a customer lives, the more likely it is that she will use both channels complementarily to each other. In combination with the abovementioned result that richer customers cancel their mobile subscription more likely than poorer ones, this points to the following interpretation: Rich customers do not need to care much about the cost due to the mobile app. Therefore, they are more inclined to try this mobile app out than poorer customers. If they like it, they will continue to use it, regardless of whether they also have an offline subscription or not, which explains the result on channel complementarity. If they do not like it, however, they will cancel their mobile subscription as easily as they have started it.

\section{Structural model}

The average hazard and retention curves (i.e., the plots of $h_{i, j}(t)$ and $\left.S_{i, j}(t)\right)$ that can be extrapolated from our results are depicted in Fig. 1a and b, respectively, for illustrative purposes. For better comprehensibility, they have been interpolated between points in time, although they are discrete in reality. From Fig. 1a it can be seen how the interdependence between both delivery channels induces a time-dependency in the cancelation hazards of subscriptions that are accompanied by a parallel subscription to 
Fig. 1 Average (a) hazard curves and (b) survival curves by subscription type a

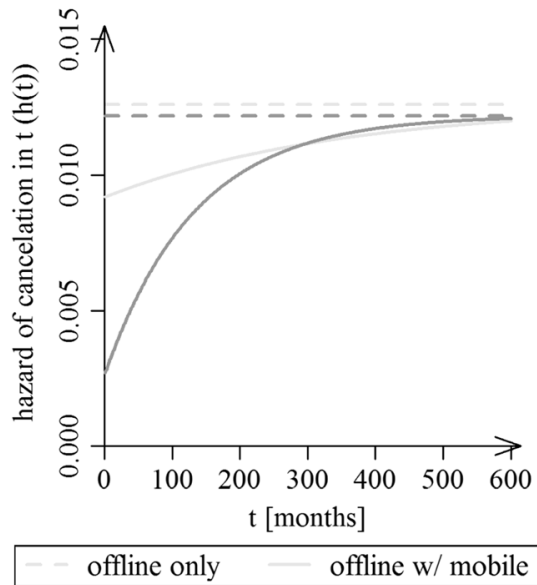

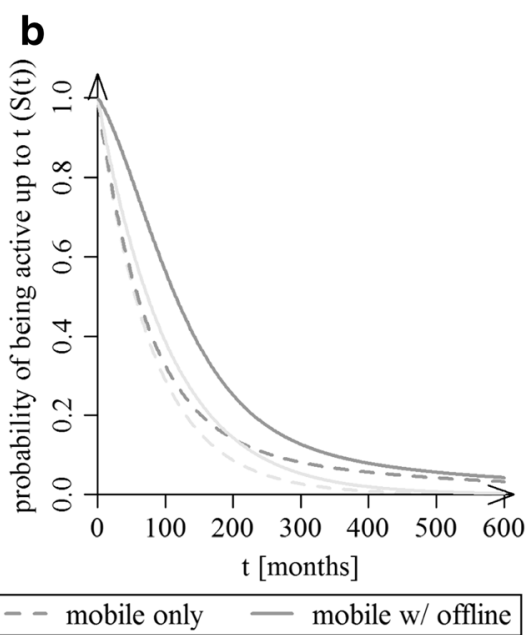

the respective other channel (dual subscriptions). If this interdependence would not exist, the hazards were constant over time and would coincide with those of single subscriptions. As a consequence, this would also apply to the corresponding survival curves. One can see from Fig. $1 \mathrm{~b}$ that this is not the case, as dual subscriptions are retained longer than single subscriptions. The figure also illustrates that, after controlling for differences in their duration up to $t_{0}$, mobile subscriptions are, on average, retained longer than offline subscriptions.

Figure 2 a shows how the hazard and survival curves translate into subscription and customer lifetimes. Since we cannot reveal the absolute values of these figures due to confidentiality, we give them in percentages of the CL of a customer with a dual subscription (a dual customer) and refer to these percentages as lifetime units. One can see that the subscription lifetime (SL) of a single offline subscription (marked as A1, 47.78 units), which equals the CL of the corresponding customer, is lower than its mobile equivalent (B1, 68.38 units). The difference $(+43.12 \%)$ describes by how much the CL of a dual customer would be higher than the CL of a customer with a single offline subscription if the channels were independent. However, since a complementary interdependence exists, the lifetime of an offline subscription is higher by $27.49 \%$ (A2) if it is accompanied by a parallel mobile subscription. The reverse effect is even stronger $(46.24 \%, \mathrm{~B} 2)$, so that the CL of a dual customer is determined by the SL of her mobile
Fig. 2 Average contribution of dual-channeling to (a) CL and (b) CLV by customer type
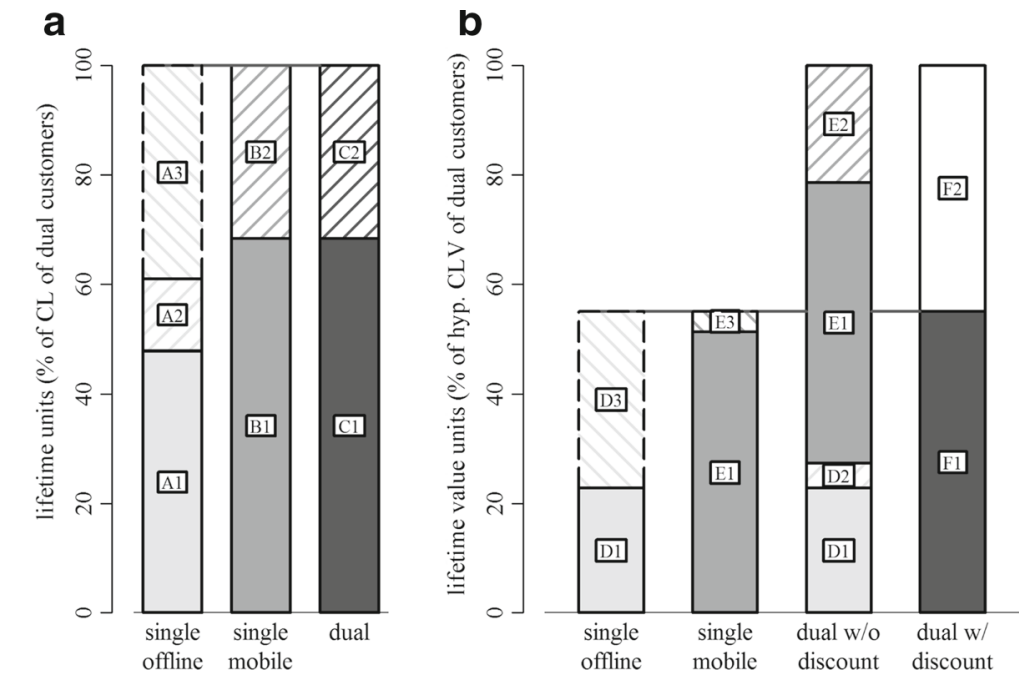

\begin{tabular}{l|c|c|c|c|c|c|c|}
\cline { 2 - 7 } \multicolumn{2}{l|}{ Legend: } & \multicolumn{3}{c|}{ CL } & \multicolumn{3}{c|}{ CLV } \\
\hline Customer type & $\begin{array}{c}\text { single } \\
\text { offline }\end{array}$ & $\begin{array}{c}\text { single } \\
\text { mobile }\end{array}$ & dual & $\begin{array}{c}\text { single } \\
\text { offline }\end{array}$ & $\begin{array}{c}\text { single } \\
\text { mobile }\end{array}$ & dual \\
\hline $\begin{array}{l}\text { Baseline values from SL(s)/SLV(s) of } \\
\text { existing subscription(s) }\end{array}$ & A1 & B1 & C1 & D1 & E1 & D1+E1 \\
\hline $\begin{array}{l}\text { + Increase due to channel complementarity on } \\
\text { SL(s)/SLV(s) of existing subscription(s) }\end{array}$ & A2 & B2 & C2 & D2 & E2 & D2+E2 \\
\hline $\begin{array}{l}\text { + Increase/decrease due to residual effects or } \\
\text { discount (F2) }\end{array}$ & A3 & 0 & 0 & D3-D2 & E3-E2 & -F2 \\
\hline = Total size & $\mathrm{A} 1+\mathrm{A} 2+\mathrm{A} 3$ & $\mathrm{~B} 1+\mathrm{B} 2$ & $\mathrm{C} 1+\mathrm{C} 2$ & $\mathrm{D} 1+\mathrm{D} 3$ & $\mathrm{E} 1+\mathrm{E} 3$ & $\mathrm{~F} 1$ \\
\hline
\end{tabular}


subscription. It can be partitioned into two components: one that describes her hypothetical CL if the channels were independent $(\mathrm{C} 1=\mathrm{B} 1)$ and one that measures the increase in $\mathrm{CL}$ that is caused by their complementarity $(\mathrm{C} 2=\mathrm{B} 2)$. An important insight now is that if a parallel mobile subscription can be sold to a customer who has a single offline subscription, her CL increases in total by $109.30 \%(\mathrm{~A} 2+\mathrm{A} 3)$, which is much greater than the reverse effect (B2). On one hand, this is simply due to the difference in the baseline SLs (B1-A1). On the other hand, such a customer's lifetime is prolonged not only due to the effect that channel complementarity exerts on the SL of her existing offline subscription but, in part, also due to the analog effect on the SL of her new mobile subscription (B2-A2). Note that, conditional on the cancelation hazards, these results do neither depend on subscription prices nor on profit margins.

These factors are taken into account when we translate the SLs and CLs to corresponding lifetime values. For their calculation, a discount rate has to be specified. We set to $0.48 \%$, which is the current 10-year-average of the interest rates of German government bonds, representing a risk-free interest rate. This is a common choice (e.g., Roemer 2006). Figure $2 b$ shows the resulting average values. Again, we cannot reveal them in absolute terms due to confidentiality, so we relate them to the CLV of a dual customer (before subtracting the discount she gets) and refer to the corresponding percentages as lifetime value units. Several insights can be gained from the figure: first, one can see that the subscription lifetime value (SLV) of a single mobile subscription (E1, 51.29 units), which equals the CLV of the customer who holds it, is much higher (by $124.66 \%$ ) than its offline equivalent (D1, 22.83 units). This is, on one hand, because of the longer SL of mobile subscriptions (after $t_{0}$ ) but, on the other hand, also due to the publisher's higher profit margin for the mobile channel.

If the channels were independent of each other, the CLV of a dual customer were given by the sum of the CLVs of a customer with a single offline subscription and a customer with a single mobile subscription minus the decrease due to the discount (F2, 44.97 units). Notably, the publisher from whom we have received our dataset would be better off in this case not to offer a parallel offline subscription at the current price to a customer with a single mobile subscription, since her CLV were greater without the parallel subscription than with it. This is because the increase in her CLV due to the new subscription would be lower than the decrease due to the discount.

Channel complementarity adds value to the subscriptions of a dual customer; the increase is greater for her mobile subscription (E2, 21.40 units, 41.71\%) than for her offline subscription (D2, 4.48 units, 19.62\%). Correspondingly, her hypothetical CLV without consideration of the discount increases by $34.91 \%$ (D2 + E2, 25.88 units). Since these changes result from changes in the SLs and CLs, it is interesting to calculate an "efficiency factor" by dividing them through the latter. This factor is again greater for the mobile channel $(\mathrm{E} 2 / \mathrm{B} 2=67.66 \%)$ than for the offline channel (D2/ $\mathrm{A} 2=34.11 \%$ ), which means that a one-unit increase in the lifetime of a dual customer's mobile subscription due to channel complementarity is more valuable to the publisher than the corresponding increase in the lifetime of the offline subscription. Regarding the hypothetical CLV, the efficiency factor is $81.83 \%$ ((D2 + E2)/C2), which means that a one-unit increase in the lifetime of a dual customer due to channel complementarity increases her hypothetical CLV by roughly 0.82 units.

Finally, the total effect of offering customers another content delivery channel can be calculated by the differences between the CLV of a dual customer after the discount has been subtracted (F1, 55.03 units) and the CLVs of customers with a single subscription. The results are as follows: If a parallel mobile subscription can be sold to a customer who has a single offline subscription, her CLV increases by $141.00 \%$ (D3, 32.20 units). In comparison, a parallel offline subscription sold to a customer who has a single mobile subscription increases her CLV by only 7.29\% (E3, 3.74 units). This is, on one hand, because of the analogous result regarding the CL and, on the other hand, due to the publisher's higher profit margin for the mobile channel. The corresponding efficiency factors of $61.65 \%(=\mathrm{D} 3 /(\mathrm{A} 2+\mathrm{A} 3))$ and $11.83 \%(=\mathrm{E} 3 / \mathrm{B} 2)$ also are in favor for the mobile channel. They mean that a one-unit increase in the CL of a customer who has a single offline subscription due to a new parallel subscription to the mobile channel corresponds to an increase in her CLV by roughly 0.62 units, while the reverse effect is much weaker (roughly 0.12 units).

\section{Conclusions}

\section{Main findings}

In this paper, we have investigated whether mobile apps can defend print media from losing customers and, thus, revenues by a model-based comparison of respective subscription and customer lifetimes and lifetime values. The answer is confirmative, as we have found a complementary effect of the mobile channel on the offline channel. This means that a parallel subscription to the mobile channel can prolong the lifetime of a subscription to the offline channel, which translates to a higher lifetime value. We have also found evidence for an even stronger reverse effect. When it comes to customer lifetimes and their values, however, we have found the increase due to a new parallel subscription to be much greater for customers who only have a subscription to the offline channel than for those who only have a subscription to the mobile channel. This is because the respective baseline values remaining at the time of analysis are lower for the former 
customers, which results from a slightly greater hazard of cancelation and, regarding lifetime values, from a lower profit margin.

We have also analyzed whether the aforementioned results differ between different customers. While we have found indications for the presence of customer heterogeneity with regard to the hazard of canceling a single subscription, the general complementarity between the offline and the mobile channel has been found to exist for all customers except for the poorest ones (or rather those living in poor regions).

\section{Generalizability}

Before we discuss the implications that these findings have for research and practice, it is necessary to elaborate on whether (or to which degree) they are generalizable. This is because they have been derived from data on only a single publisher (of a respected German national newspaper), which also represent only a single point in time of operation. These two restrictions may limit the generalizability with regard to the following aspects:

First, one can ask how representative the point in time is even for the focal publisher. This would not be the case, for example, if it would coincide with a special advertising campaign by a competitor. However, we are not aware of any such special circumstances in our case. Also, while it is likely that seasonal or special effects (e.g., when a cruel terror attack occurred) influence daily purchases of newspapers by nonsubscribers, it is unlikely that they strongly influence customers' cancelation behavior.

The second question that arises is how much the results depend on the characteristics of the printed and the mobile version of the newspaper, or rather the difference between these characteristics. For the publisher we have considered, both versions are identical in terms of content. This is an almost ideal situation for isolating the value added by mobile, but not all publishers follow this approach, and if the two versions differ strongly, it is not clear whether our findings will still hold. However, there is a good reason to assume so: We have argued above that the two versions are complementary likely because they are adapted for different niches (e.g., at home use vs. use in a crowded bus). If this is true, the complementarity should not be influenced much by differences between the two versions (as long as they still both fulfill the customers' needs).

Third, the question arises to which degree our results hold for other publishers who offer a similar product through the observed channels. In this case, a distinction has to be made between results regarding channel complementarity and its impact on CLs on one hand and on CLVs on the other hand. As far as CLs are concerned, there is no reason to assume that complementarity would not hold. Results on CLVs depend, by their nature, on the focal publisher's prices and profit margins and on the discount offered to customers when they subscribe to several channels. Therefore, they will certainly vary in magnitude between publishers. However, since they are determined by CLs, our results imply that a mobile app should increase CLVs also for other newspaper publishers as long as the discount they offer for dual subscriptions is not too large (the exact maximum amount can be determined from Fig. 2b).

Separate research is necessary for very different products offered via the observed channels (e.g., a mobile plan subscription that can be purchased and maintained mobile or offline). The same is true for subscriptions to products offered via different media (e.g., a sports channel that can be consumed via TV or a mobile app). Still, such research can be carried out rather easily by applying our model to corresponding data.

\section{Implications and limitations}

The main practical implication of this paper is that offering a mobile app can help publishers to retain their customers for a longer time. For many of them, this will translate to higher CLVs and, thus, to higher revenues, such as it is the case for the publisher we have considered. However, it is important to note that one cannot infer from this that offering a mobile app is always advisable. This is, on one hand, due to the costs of developing and maintaining the mobile app and, on the other hand, due to some limitations of our approach: Most importantly, we have only analyzed subscription cancelation behavior (that is, existing customers), while interdependencies between content delivery channels may also exist regarding subscription behavior (that is, new customers). Furthermore, we have defined CLVs based on the prices and profit margins of subscriptions, while publishers can profit from customers also in other ways (e.g., from advertising or product referrals). However, the resolution of these two limitations can be expected to lead to higher figures for the CLVs rather than to lower ones, which is in favor of offering a mobile app.

Publishers can, moreover, use our model to investigate the relationship between any two content delivery channels they serve in their individual context. This is what we recommend. In fact, the publisher from whom we have received our dataset relies on calculations that are similar to the ones we have made, though less rigorous.

In the case that a publisher decides to serve the mobile channel, our results also inform him on how he should announce this offer to existing customers. Since we have found that income (as represented by a BPI) is the only demographic that affects the cancelation hazard of a mobile subscription or channel complementarity, there is no need to target, e.g., certain age groups. Rather, the publisher should focus on keeping people from richer regions as mobile app customers, since they are more volatile than people in poor regions are, as shown above. 
Our work also has implications for research. To the best of our knowledge, it is the first study to evaluate the relationship of the offline channel and the mobile channel and its determinants based on real performance data. Therefore, our results confirm from the publisher's perspective what some authors (see the related-research section) have found in surveys of customers.

Future research can also use our model. It is neither bound to the offline and the mobile channel nor to certain industries. Rather, it can be applied to almost any subscription data, so that it should be applicable in many sectors that involve subscriptions. Our model informs researchers and practitioners about the (determinants of the) hazard that a subscription to a certain channel is canceled, the interdependence between channels, the impact of this interdependence on CLs and CLVs, and total CLs and CLVs. Therefore, it can be used to decide which channels should be served.

However, our model currently is able to account only for two channels, while publishers may serve more channels in practice. In particular, we have not considered the online channel in our study. Future research can, therefore, extend the model to three or even more channels and include the online channel for a broader analysis of the various potential relationships.

Open Access This article is distributed under the terms of the Creative Commons Attribution 4.0 International License (http:// creativecommons.org/licenses/by/4.0/), which permits unrestricted use, distribution, and reproduction in any medium, provided you give appropriate credit to the original author(s) and the source, provide a link to the Creative Commons license, and indicate if changes were made.

\section{References}

Althaus, S. L., \& Tewksbury, D. (2000). Patterns of internet and traditional news media use in a networked community. Political Communication, 17(1), 21-45.

Anderson, E. W., \& Mittal, V. (2000). Strengthening the satisfactionprofit chain. Journal of Service Research, 3(2), 107-120.

Ansari, A., Mela, C. F., \& Neslin, S. A. (2008). Customer channel migration. Journal of Marketing Research, 45(1), 60-76.

Bang, Y., Lee, D.-J., Han, K., Hwang, M., \& Ahn, J.-H. (2013). Channel capabilities, product characteristics, and the impacts of mobile channel introduction. Journal of Management Information Systems, 30(2), 101-126.

Berger, P. D., \& Nasr, N. I. (1998). Customer lifetime value: Marketing models and applications. Journal of Interactive Marketing, 12(1), $17-30$.

Bertrand, M., \& Mullainathan, S. (2001). Do people mean what they say? Implications for subjective survey data. The American Economic Review, 91(2), 67-72.

Boehm, M. (2008). Determining the impact of internet channel use on a customer's lifetime. Journal of Interactive Marketing, 22(3), 2-22.

Böhmer, M., Hecht, B., Schöning, J., Krüger, A., \& Bauer, G. (2011). Falling asleep with angry birds, Facebook and kindle: A large scale study on mobile application usage. In: M. Bylund, O. Juhlin, \& Y.
Fernaeus (Eds.), Proceedings of the 13th international conference on human computer interaction with mobile devices and services. New York: ACM, pp. 47-56.

Bolton, R. N. (1998). A dynamic model of the duration of the customer's relationship with a continuous service provider: The role of satisfaction. Marketing Science, 17(1), 45-65.

Broyden, C. G. (1970). The convergence of a class of double-rank minimization algorithms -1 . General considerations. IMA Journal of Applied Mathematics, 6(1), 76-90.

Chan, J. K.-C. (2005). Lifestyles, reliance on traditional news media and online news adoption. New Media \& Society, 7(3), 357-382.

Chan, M. (2015). Examining the influences of news use patterns, motivations, and age cohort on mobile news use: The case of Hong Kong. Mobile Media \& Communication, 3(2), 179-195.

Chyi, H. I., \& Chadha, M. (2012). News on new devices. Journalism Practice, 6(4), 431-449.

De Waal, E., \& Schoenbach, K. (2010). News sites' position in the mediascape: Uses, evaluations and media displacement effects over time. New Media \& Society, 12(3), 477-496.

Destatis (2016). Income, receipts, expenditure. Official Website of the German Federal Statistical Office (Statistisches Bundesamt). https:// Www.destatis.de/EN/FactsFigures/SocietyState/ I n c o m e Consumption Living Conditions/ IncomeConsumptionLivingConditions.html.

Dimmick, J., Chen, V., \& Li, Z. (2004). Competition between the internet and traditional news media: The gratification-opportunities niche dimension. Journal of Media Economics, 17(1), 19-33.

Donkers, B., Verhoef, P. C., \& de Jong, M. G. (2007). Modeling CLV: A test of competing models in the insurance industry. Quantitative Marketing and Economics, 5(2), 163-190.

Edmonds, R., Guskin, E., Mitchell, A., \& Jurkowitz, M. (2013). 2013. By the numbers. Pew Research Center, The State of the News Media 2013, rider Newspapers. http://stateofthemedia.org/2013/ newspapers-stabilizing-but-still-threatened/newspapers-by-thenumbers/.

Elangovan, N., \& Gupta, H. (2015). Impact of smartphone news apps on print media - A twin TAM framework. Journal of Business and Management, 17(4), 1-9.

Fader, P. S., \& Hardie, B. G. S. (2010). Customer-base valuation in a contractual setting: The perils of ignoring heterogeneity. Marketing Science, 29(1), 85-93.

Fidler, R. F. (1997). Mediamorphosis: Understanding new media. Journalism and communication for a new century. Thousand Oaks: Pine Forge Press.

Fletcher, R. (1970). A new approach to variable metric algorithms. The Computer Journal, 13(3), 317-322.

Gensler, S., Leeflang, P., \& Skiera, B. (2012). Impact of online channel use on customer revenues and costs to serve: Considering product portfolios and self-selection. International Journal of Research in Marketing, 29(2), 192-201.

GfK (2016). Market data Germany. Germany: GfK SE. http://www.gfkgeomarketing.de/en/market_data/market_data_by_country/ germany.html.

Goldfarb, D. (1970). A family of variable-metric methods derived by variational means. Mathematics of Computation, 24(109), 23-26.

Gupta, S., Lehmann, D. R., \& Stuart, J. A. (2004). Valuing customers. Journal of Marketing Research, 41(1), 7-18.

Hennig-Thurau, T., Malthouse, E. C., Friege, C., Gensler, S., Lobschat, L., Rangaswamy, A., \& Skiera, B. (2010). The impact of new media on customer relationships. Journal of Service Research, 13(3), 311330.

Iliescu, D. C., Garrow, L. A., \& Parker, R. A. (2008). A hazard model of US airline passengers' refund and exchange behavior. Transportation Research Part B: Methodological, 42(3), 229-242. 
Keane, T. J., \& Wang, P. (1995). Applications for the lifetime value model in modern newspaper publishing. Journal of Direct Marketing, 9(2), 59-66.

Kumar, V., \& Reinartz, W. (2012). Customer relationship management: Concept, strategy, and tools (2nd ed.). Springer: Dordrecht.

Kumar, V., \& Venkatesan, R. (2005). Who are the multichannel shoppers and how do they perform? Correlates of multichannel shopping behavior. Journal of Interactive Marketing, 19(2), 44-62.

Misra, K. B. (1992). Reliability analysis and prediction: A methodology oriented treatment. Amsterdam: Elsevier.

Nagelkerke, N. J. D. (1991). A note on a general definition of the coefficient of determination. Biometrika, 78(3), 691-692.

Neslin, S. A., \& Shankar, V. (2009). Key issues in multichannel customer management: Current knowledge and future directions. Journal of Interactive Marketing, 23(1), 70-81.

Roemer, E. (2006). The impact of dependence on the assessment of customer lifetime value in buyer-seller relationships. Journal of Marketing Management, 22(1-2), 89-109.

Schmittlein, D. C., Morrison, D. G., \& Colombo, R. (1987). Counting your customers: Who are they and what will they do next? Management Science, 33(1), 1-24.

Shankar, V., \& Balasubramanian, S. (2009). Mobile marketing: A synthesis and prognosis. Journal of Interactive Marketing, 23(2), 118129.

Shanno, D. F. (1970). Conditioning of quasi-Newton methods for function minimization. Mathematics of Computation, 24(111), 647-656.
Simon, D. H., \& Kadiyali, V. (2007). The effect of a magazine's free digital content on its print circulation: Cannibalization or complementarity? Information Economics and Policy, 19(3-4), 344-361.

Therneau, T., Crowson, C., \& Atkinson, E. (2017). Using time dependent covariates and time dependent coefficients in the Cox model. https:// cran.r-project.org/web/packages/survival/vignettes/timedep.pdf.

Thorson, E., Shoenberger, H., Karaliova, T., Kim, E. A., \& Fidler, R. (2015). News use of mobile media: A contingency model. Mobile Media \& Communication, 3(2), 160-178.

Westlund, O., \& Färdigh, M. A. (2011). Displacing and complementing effects of news sites on newspapers 1998-2009. The International Journal on Media Management, 13(3), 177-194.

Westlund, O., \& Färdigh, M. A. (2015). Accessing the news in an age of mobile media: Tracing displacing and complementary effects of mobile news on newspapers and online news. Mobile Media \& Communication, 3(1), 53-74.

Winter, P., Alpar, P., \& Kunert, C. (2016). Can mobile apps defend print media? Research Papers. 133. http://aisel.aisnet.org/ecis2016 rp/ $133 /$.

Yang, S., \& Ghose, A. (2010). Analyzing the relationship between organic and sponsored search advertising: Positive, negative, or zero interdependence? Marketing Science, 29(4), 602-623.

Zeelenberg, M., \& Pieters, R. (2004). Beyond valence in customer dissatisfaction: A review and new findings on behavioral responses to regret and disappointment in failed services. Journal of Business Research, 57(4), 445-455. 